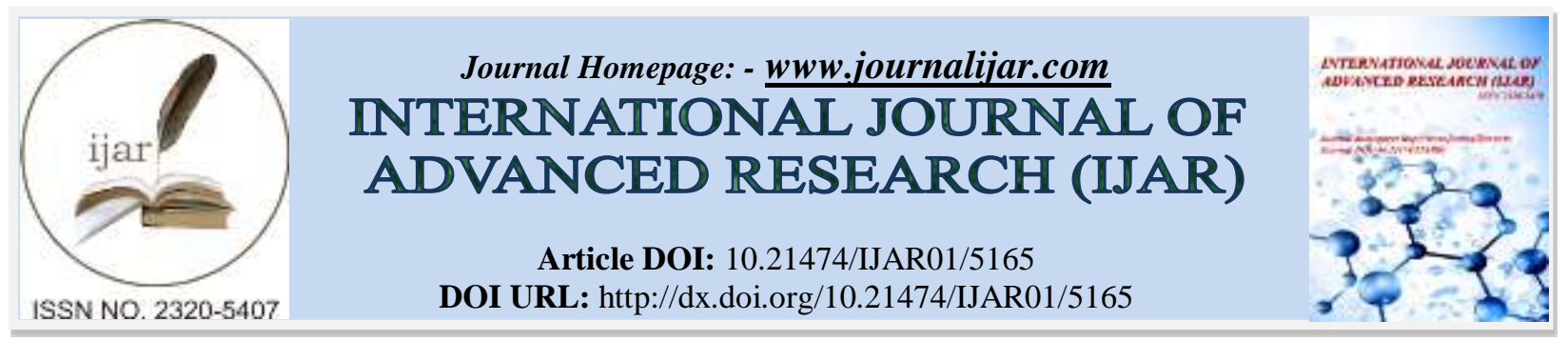

RESEARCH ARTICLE

\title{
OVERVIEW OF GLARE TYPES AND THEIR RELATIONSHIP WITH MACULAR PIGMENT OPTICAL DENSITY.
}

Chris Putnam.

UMSL College of Optometry, One University Blvd, 417 Marillac Hall, St Louis, MO 63121.

\section{Manuscript Info}

Manuscript History

Received: 14 June 2017

Final Accepted: 16 July 2017

Published: August 2017

\section{Abstract}

Reduced visual performance due to intraocular scatter and environmental glare conditions are two of the most commonly reported symptoms in a clinical setting. Study of glare and the neural processes that underlie the phenomena have been studied since the early $19^{\text {th }}$ century. This overview provides a historical perspective of glare and intraocular scatter, types and definitions, role of ophthalmic materials in glare mitigation and the role of macular pigment in glare amelioration. The 3 hypothesized roles of macular pigment (MP) to include Retinal Protection, Neural Efficiency and Optical Enhancement as well as an examination of the 3 subsets of Optical Enhancement as it related to glare reduction will also be explored. Existing literature has explored the detailed spatial and chemical properties of MP and this review will discuss how differing glare types can be affected by differing MP spatial distributions and how tailored oral supplementation of MP constituents can enhance the glare reduction benefits.

Copy Right, IJAR, 2017,. All rights reserved.

\section{Introduction:-}

Early $19^{\text {th }}$ century biologist and physicist Johann von Goethe devoted a number of pages in his Theory of Colours to subjective haloes explained as 'conflict between mover and moved' in reference to glare as a neural disturbance process ${ }^{1}$. Nearly 15 years later, Czech anatomist and physiologist Johannes Purkinje attributed the veiling appearance to light scattering in the ocular media ${ }^{1}$. Further work in scientific glare research was shown by Hermann von Helmholtz with his 1852 paper outlining 2 possibilities of the etiology of disability glare: neural vs. optical ${ }^{1}$. His work described the optical scattering processes that, in his view, must certainly exist and only further studies would show the role of neural processes.

The foundation created by these pioneers in contemporary glare understanding led to the development of the technique known as "equivalent background' utilized by PW Cobb in his 1911 paper on the influence of illumination on visual acuity ${ }^{2}$. The visibility of objects was measured with and without a veiling mask allowing for 
a quantifiable glare measurement. This same technique was employed by Holladay and Stiles leading to the now well-known Stiles-Holladay disability glare formula for a point-glare source:

$\mathrm{L}_{\mathrm{eq}}=10 \mathrm{E}_{\text {glare }} /$ theta $^{2}$

In which $\mathrm{L}_{\mathrm{eq}}$ is the equivalent veiling background in $\mathrm{cd} / \mathrm{m}^{2}, \mathrm{E}_{\text {glare }}$ is the illuminance at the eye from the glare source in lux, and theta which is the angular distance between line of sight and glare source in degrees ${ }^{2}$.

The derived formula reinforced the assumption that the proportionality between $\mathrm{L}_{\mathrm{eq}}$ and $\mathrm{E}_{\text {glare }}$ indicates that disability glare is an optical phenomena caused by light scattering within optical media and not a neural process. As with any simplified explanation, variations within measurements led other investigators to report deviations from the proposed rigid proportionality of $\mathrm{L}_{\mathrm{eq}}$ with $\mathrm{E}_{\text {glare }}$ and the emerging discoveries of inhibitory neural networks within the retina reviving some of the neural theories of glare etiology.

Additional experiments controlled for influences of pupil size and eye movements resulting in no differences from earlier proposed values of equivalent veiling background and illuminance at the plane of the eye were identified ${ }^{3}$. More importantly, quantitative evidence of forward scattered light from the cornea, lens, and fundus could explain nearly all of equivalent veiling background in agreement with the Stiles-Holladay equation ${ }^{3}$.

\section{Scatter:-}

Light scattering results from particle interactions that occur along an electromagnetic wave path that simultaneously removes energy from the incident wave and emits that energy as a solid angle from the particle. Scattering only occurs when the particle's refractive index differs from the surrounding medium (e.g. smog, haze, vapor). The amount of scatter depends on the particle type and concentration within the atmosphere. This particle-dependent scatter largely dictates the quality of vision in an outdoor environment. Rayleigh (elastic / small particle) and Mie (inelastic / large particle) scattering are essential theories for describing the effects of light within the environment ${ }^{4}$. If scatter within the eye is wavelength dependent as it is in the clear atmosphere, then selectively screening the highly scattered short-wavelength light would improve the retinal image. However, studies of proposed models for intraocular scatter and presented empirical evidence documenting a predominance of Mie scatter within the eye ${ }^{5,6}$. Wooten et al. stated that all evidence suggests glare is independent of wavelength due to the light scattering in the eye occurring at structures large with respect to wavelength ${ }^{7}$. Due to the wavelength-independence of Mie scattering, intraocular straylight contributions from short wavelength light should be similar to longer wavelength light. A paper by Vos reviewed glare and the potential for in vivo wavelength dependence of intraocular scattering. His results concluded that wavelength independence of entopic scatter seems to be resolved. The predominance of Mie-type scattering within the eye would predict greater forward scattering (toward the retina) than backscatter (backwards towards the source) ${ }^{8}$. According to van den Berg et al., forward scatter rather than backscatter results in corresponding functional visual impairment leading to a number of glare-related complaints ${ }^{9}$. As a consequence, there is may exist significant forward scatter of short wavelength light and relatively less backward scatter shortwavelength scatter to be absorbed by macular pigment ${ }^{10}$.

Franssen et al. discussed intraocular straylight defined as a "straylight parameter" indicated by $s\left[\mathrm{deg}^{2} / \mathrm{sr}^{11}\right.$. The straylight parameter indicates how much of the incident light arriving within the eye is scattered by inhomogeneity within the internal optical elements of the eye. This loss of focus may cause a veiling luminance across the retina leading to a decline of resulting image contrast ${ }^{12}$. Fletcher et al. reviewed the aspects of intraocular scatter in relation to veiling luminance and glare disability ${ }^{13}$. Disability glare, as defined by the CIE corresponds to retinal straylight which is identified as equivalent luminance that has a similar visual effect as the glare source at some angular distance $^{8}$.

Nouritt et al. discussed in detail the interaction among intraocular scatter, glare, and aberrations ${ }^{14}$. Light propagating through the eye will be scattered by inhomogeneity and this scatter can be backward or forward. Backward light scatter will primarily reduce the amount of light reaching the retina while forward scatter will reduce contrast (both chromatic and achromatic) at the retina by increasing the spread of light. Contrast sensitivity loss shows a correlation with forward scatter although they are not directly proportional. Aguirre et al. found that the strongest correlation between reduction of contrast sensitivity and scatter is obtained in the presence of a glare source controlled for constant luminance and wavelength ${ }^{15}$. Vos concluded that intraocular scatter was independent of wavelength due, in part, to the Mie scattering that predominated within the eye ${ }^{2}$. However, Coppens et al. used an 'accurate compensation' approach and found that intraocular forward scatter does have a wavelength dependence influenced by the pigmentation within the eye ${ }^{10}$. 


\section{Types and Definitions:-}

Glare can be classified into several different types including ${ }^{1)}$ disability, ${ }^{2)}$ discomfort, ${ }^{3)}$ scotomatic (photostress), ${ }^{4)}$ dazzling and ${ }^{5)}$ dysphotopsia. This review will focus on the three areas of glare with the most existing literature: disability, discomfort and scotomatic.

\section{Disability Glare:-}

Disability glare is defined as loss of retinal image contrast as a result of intraocular straylight ${ }^{16}$. A decrease in visual performance may be caused by the loss of retinal image contrast due to surface reflections or bright luminance sources creating increased forward scatter of light within the eye. Decrements in visual performance may result from both veiling illuminance that reduces the object contrast as well as photopigment depletion and regeneration rates. Stringham et al. defined the origins of disability glare as forward scattering of light resulting from illumination at the retina that directly reduces image contrast ${ }^{17}$. Their study recognized that disability glare has a significant dependence on the overall luminance created by a glare source. Forward scattering or straylight is not necessarily the sole cause of disability glare symptoms. At smaller angles of incidence, neural inhibition at the retinal level can contribute to disability glare ${ }^{2,18}$.

\section{Discomfort Glare:-}

Discomfort glare has been characterized as exacerbation or generation of pain as a consequence of light exposure which does not necessarily impair object visibility. Digre and Brennan defined photophobia as a sensory state in which light causes discomfort in the eye or head possibly involving an avoidance reaction without overt pain ${ }^{19}$. The authors also drew a distinction with the term photo-oculodynia used to describe light-induced pain from a normally non-painful source such as ambient lighting. Wooten and Stringham have evaluated the characteristics of a glare source as they related to discomfort glare ${ }^{20,21}$. The studies showed that the degree of visual discomfort was significantly higher if the glare source contained short wavelength light compared to mid and long wavelength light. According to Lapid-Gortzak et al., clinical complaints of photophobia may be a result of increased intraocular scatter $^{22}$. The proposal that short-wavelength light is a significant component to the ocular discomfort related to exposure from a glare source has been extensively reviewed in the literature ${ }^{23}$. Bargary et al. evaluated the effects of discomfort glare and its relationship to cortical hyperexcitability finding that discomfort glare decreases visual performance even when controlling for disability glare ${ }^{24}$.

\section{Photostress (Scotomatic) Glare:-}

The human visual system is adept at detecting at luminance levels that span approximately 8 orders of magnitude ${ }^{25}$. Retinal adaptation adjusts the range of visual sensitivity to prevailing luminance. Perceptual difficulties occur when the visual system must adapt briskly to these sudden changes. Glare is caused by light entering the eye that does not aid vision and is most commonly luminance that is too intense or variable across the visual field ${ }^{4}$. Photostress or scotomatic glare occurs when a light source quickly decreases visual sensitivity. It is caused primarily by rapid bleaching and subsequent slower regeneration of retinal photopigments. Photostress glare is a process which may persist following light exposure due to time required to return.

\section{Dazzling Glare:-}

Dazzling glare is a form of discomfort glare associated with disability glare. It is commonly encountered as high retinal illuminance across the visual field in scenarios such as expanses of snow or water and facing the sun when it is low in the horizon ${ }^{1}$. Dazzling glare typically results in a light avoidance behavior. Areas of study that encompass the physiologic effects created through dazzling glare can be found in laser eye protection and anti-personnel laser systems. Sheehy reported the precipitous loss in visual performance resulting from wavelengths within the visible spectrum $^{26}$. His study detailed the characteristics of eye protection necessary based on visual performance.

\section{Dysphotopsia Glare:-}

Streaks, flare, central flash, and haloes from a point source of light represent positive dysphotopsia and dark crescents or shadows represent negative dysphotopsia. Both positive and negative dysphotopsia can be associated with intraocular lens (IOL) implantation stemming from the square-edge design of the optics, placement of the IOL within the capsular bag, or diameter of the IOL relative to the capsulorhexis diameter. However, a few of the positive dysphotopsias, such as flare and haloes (in a monofocal IOL), have been described in the literature as having a higher order aberration etiology ${ }^{27}$. In which case, the established dichroic and polarizing properties of MP may have an ameliorating effects following MPOD augmentation ${ }^{28}$. 
Table 1:- summarizes the five types of glare commonly encountered in a clinical setting and discusses the etiology, associated conditions, clinical assessment, ophthalmic material options and potential amelioration though macular pigment for each.

\begin{tabular}{|c|c|c|c|c|c|}
\hline & Etiology & $\begin{array}{l}\text { Associated } \\
\text { Clinical } \\
\text { Conditions }\end{array}$ & $\begin{array}{l}\text { Clinical } \\
\text { Assessment }\end{array}$ & $\begin{array}{l}\text { Ophthalmic } \\
\text { Options }\end{array}$ & $\begin{array}{l}\text { Potential MP } \\
\text { Amelioration }\end{array}$ \\
\hline $\begin{array}{l}\text { Disability } \\
\text { Glare }\end{array}$ & $\begin{array}{l}\text { Entopic } \\
\text { scattering } \\
\text { creating } \\
\text { veiling } \\
\text { luminance } \\
\text { resulting in } \\
\text { loss of retinal } \\
\text { contrast }\end{array}$ & $\begin{array}{l}\text { Cataract } \\
\text { formation, corneal } \\
\text { dystrophies, } \\
\text { retinal disease }\end{array}$ & $\begin{array}{l}\begin{array}{l}\text { Disability } \\
\text { Index }\end{array} \text { (DGIare } \\
\text { Brightness Acuity } \\
\text { Tester (BAT) } \\
\text { Berkley Glare Test } \\
\text { Optec 6500 } \\
\text { CSV-1000HGT } \\
\text { C-Quant (Oculus) } \\
\text { Mesotest (Oculus) } \\
\text { Nyktotest } \\
\text { (Rodenstock) }\end{array}$ & $\begin{array}{l}\text { Corning Protective } \\
\text { Filter (CPF) tints, } \\
\text { polarized } \\
\text { sunglasses, Anti- } \\
\begin{array}{lr}\text { Reflective } & (\mathrm{AR}) \\
\text { coating, } & \text { Higher } \\
\text { Order Aberration } & \\
(\mathrm{HOA}) \text { correction }\end{array}\end{array}$ & $\begin{array}{l}\text { Short } \\
\text { wavelength } \\
\text { filtration } \\
\text { Dichroic } \\
\text { Polarization } \\
\text { properties }\end{array}$ \\
\hline $\begin{array}{l}\text { Discomfort } \\
\text { Glare }\end{array}$ & $\begin{array}{l}\text { Widely } \\
\text { varied retinal } \\
\text { illuminance } \\
\text { levels } \\
\text { leading to } \\
\text { pupillary } \\
\text { fluctuations }\end{array}$ & $\begin{array}{l}\text { Albinism, aniridia, } \\
\text { corneal dystrophy, } \\
\text { ARM, DR, cone } \\
\text { dystrophy, POHS }\end{array}$ & $\begin{array}{l}\text { National Eye } \\
\text { Institute Visual } \\
\text { Function } \\
\text { Questionnaire } \\
\text { LOCS III } \\
\text { Activities of Daily } \\
\text { Living scale } \\
\text { C-Quant (Oculus) }\end{array}$ & $\begin{array}{l}\text { Polarized } \\
\text { sunglasses, CPF } \\
\text { tints, visor, side } \\
\text { shields, AR coating }\end{array}$ & $\begin{array}{l}\begin{array}{l}\text { Short } \\
\text { wavelength } \\
\text { filtration }\end{array} \\
\text { Dichroic } \\
\text { Polarization } \\
\text { properties }\end{array}$ \\
\hline $\begin{array}{l}\text { Scotomatic } \\
\text { Glare } \\
\text { (Photostress) }\end{array}$ & $\begin{array}{l}\text { High retinal } \\
\text { illuminance } \\
\text { across large } \\
\text { retinal area }\end{array}$ & $\begin{array}{lr}* * \text { Not associated } \\
\text { with } & \text { specific } \\
\text { clinical conditions }\end{array}$ & $\begin{array}{l}\text { Photostress } \\
\text { Recovery Test } \\
\text { Eger Macular } \\
\text { Stressometer } \\
\text { MAP using HVF }\end{array}$ & $\begin{array}{l}\text { **Not a commonly } \\
\text { encountered } \\
\text { circumstance in } \\
\text { natural } \\
\text { environments }\end{array}$ & $\begin{array}{l}\text { Short } \\
\text { wavelength } \\
\text { filtration } \\
\text { Dichroic } \\
\text { Polarization } \\
\text { properties }\end{array}$ \\
\hline $\begin{array}{l}\text { Dazzling } \\
\text { Glare } \\
\text { (Adaptation) }\end{array}$ & $\begin{array}{l}\text { High retinal } \\
\text { illuminance } \\
\text { in focal } \\
\text { region } \\
\text { leading to } \\
\text { chromophore } \\
\text { bleaching } \\
\text { and } \\
\text { afterimages }\end{array}$ & $\begin{array}{l}\text { Retinitis } \\
\text { Pigmentosa, } \\
\text { Stargardt's } \\
\text { disease, Age- } \\
\text { Related } \\
\text { Maculopathy, } \\
\text { Retinal } \\
\text { Detachment, } \\
\text { Diabetic } \\
\text { Retinopathy, } \\
\text { Presumed Ocular } \\
\text { Histoplasmosis, } \\
\text { cone dystrophy }\end{array}$ & $\begin{array}{l}\text { NEI VFQ } \\
\text { Activities of Daily } \\
\text { Living } \\
\text { (ADVS) }\end{array}$ & $\begin{array}{lr}\text { Neutral density } \\
(\mathrm{ND}) & \text { filters, } \\
\text { wavelength } & \text { specific } \\
\text { tints }\end{array}$ & $\begin{array}{l}\text { Singlet } \mathrm{O}_{2} \text { and } \\
\text { free radical } \\
\text { scavenging in } \\
\text { disease etiology } \\
\text { Dichroic / } \\
\text { Polarization } \\
\text { properties }\end{array}$ \\
\hline $\begin{array}{l}\text { Dysphotopsia } \\
\text { Glare }\end{array}$ & $\begin{array}{l}\text { Oblique rays } \\
\text { partially } \\
\text { refracted by } \\
\text { the lens edge } \\
\text {, backscatter, } \\
\text { coma, } \\
\text { spherical } \\
\text { aberrations }\end{array}$ & $\begin{array}{l}\text { Intraocular lens } \\
\text { replacement, } \\
\text { corneal } \\
\text { irregularities, }\end{array}$ & $\begin{array}{l}\text { Corneal imaging, } \\
\text { high-frequency } \\
\text { ultrasound, Optical } \\
\text { Cohernce } \\
\text { Tomography } \\
\text { imaging }\end{array}$ & $\begin{array}{l}\text { Intra-ocular lens } \\
(\mathrm{IOL}) \\
\text { repositioning, } \\
\text { replacement } \\
\text { piggyback }\end{array}$ & $\begin{array}{l}\text { Dichroic } \\
\text { Polarization } \\
\text { properties }\end{array}$ \\
\hline
\end{tabular}

Table 1

Five primary glare types and potential role of putative role of macular pigment function 


\section{Ophthalmic approach to glare reduction:-}

Mainster and Turner reviewed several effective optical glare countermeasures available for daytime situations which included, polarized filters, anti-reflective coatings, neutral density filters, higher-order aberration correction and wavelength specific tints ${ }^{23}$. Kvansakul et al. discussed the use of yellow filtering extending photopic range in an effort to extend the attributes of improved contrast sensitivity and spatial resolution associated with cone function ${ }^{29}$. Polarized filters are related to effective glare reduction caused by reflected incident light and have demonstrated robust reduction in disability and discomfort glare albeit with an approximately $50 \%$ reduction in photopic luminous transmission. Other ophthalmic options for glare reduction include anti-reflective (AR) coatings that include multilayer interference coatings, graded index coatings and quarter-wave coatings. Previous attempts to reduce glare in the visible spectrum by high-order aberration correction have also pursued by iZon High Definition Lenses. Published literature has shown corrections of higher order aberrations up to the $6^{\text {th }}$ Zernike polynomial have resulted in increased CS under glare and decreased glare disability ${ }^{30}$. Clinical off-label use of brimonidine $0.10 \%$ to decrease overall pupil diameter has also shown some benefit in the reduction of glare disability ${ }^{31,32}$. Table 2 summarizes visual function measures commonly affected by glare and compares advantages and disadvantages of each measure.

\begin{tabular}{|c|c|c|c|c|c|}
\hline & $\begin{array}{l}\text { Photopic / } \\
\text { Mesopic } \\
\text { Visual Acuity }\end{array}$ & $\begin{array}{l}\text { Letter Contrast } \\
\text { Sensitivity }\end{array}$ & $\begin{array}{l}\text { Grating Contrast } \\
\text { Sensitivity }\end{array}$ & $\begin{array}{l}\text { Glare } \\
\text { Sensitivity }\end{array}$ & $\begin{array}{l}\text { Intraocular } \\
\text { Scatter } \\
\text { Testing }\end{array}$ \\
\hline $\begin{array}{l}\text { Clinical } \\
\text { Assessment }\end{array}$ & $\begin{array}{l}\text { ETDRS chart } \\
\text { (Precision } \\
\text { Vision) } \\
\text { Bailey-Lovie } \\
\text { chart } \\
\text { (National } \\
\text { Vision } \\
\text { Research } \\
\text { Institute) }\end{array}$ & $\begin{array}{l}\text { Pelli-Robson chart } \\
\text { (Haag-Streit) } \\
\text { Mars letter Contrast } \\
\text { Sensitivty (Mars } \\
\text { Perceptrix Corp.) } \\
\text { SKILL card (Smith- } \\
\text { Kettlewell Eye } \\
\text { Research Institute) } \\
\text { Holladay Contrast } \\
\text { Acuity test (Stereo } \\
\text { Optical, Inc.) }\end{array}$ & $\begin{array}{lr}\text { CSV-1000E chart } \\
\text { (Vector Vision) } \\
\text { Optec } & \text { 6500P } \\
\text { (Stereo } & \text { Optical, } \\
\text { Inc.) } & \\
\text { FACT chart (Vision } \\
\text { Sciences } & \text { Research } \\
\text { Corp.) } & \end{array}$ & $\begin{array}{l}\text { Optec 6500P } \\
\text { (Stereo Optical, } \\
\text { Inc.) } \\
\text { CSV-1800 } \\
\text { (Vision Sciences } \\
\text { Research Corp.) } \\
\text { CSV-1000HGT } \\
\text { (Vector Vision) }\end{array}$ & $\begin{array}{l}\text { C-Quant } \\
\text { (Oculus) }\end{array}$ \\
\hline Advantages & $\begin{array}{l}\text { Efficient } \\
\text { predictor of } \\
\text { high } \\
\text { resolution } \\
\text { tasks }\end{array}$ & $\begin{array}{ll}\text { Increased } & \\
\text { correlation } & \text { to } \\
\text { natural viewing } \\
\text { conditions }\end{array}$ & $\begin{array}{l}\text { Assessment of } \\
\text { entire modulation } \\
\text { transfer function }\end{array}$ & $\begin{array}{lr}\text { Assessment } & \text { of } \\
\text { sensitivity } & \text { loss } \\
\text { due } & \text { to } \\
\text { intraocular } & \\
\text { scatter } & \end{array}$ & $\begin{array}{l}\text { Allows } \\
\text { repeatable, } \\
\text { numeric } \\
\text { results }\end{array}$ \\
\hline Disadvantages & 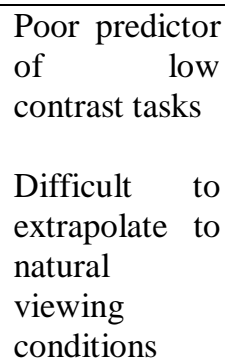 & $\begin{array}{l}\text { Time-consuming in } \\
\text { clinical setting } \\
\text { Greater variability } \\
\text { than photopic and } \\
\text { mesopic visual } \\
\text { acuity }\end{array}$ & $\begin{array}{l}\text { Time-consuming in } \\
\text { clinical setting } \\
\text { Greater variability } \\
\text { than photopic and } \\
\text { mesopic visual } \\
\text { acutiy }\end{array}$ & $\begin{array}{l}\text { No } \\
\text { standardization } \\
\text { of results } \\
\text { Highly variable } \\
\text { results }\end{array}$ & $\begin{array}{l}\text { Lack of } \\
\text { established } \\
\text { clinical } \\
\text { guidelines }\end{array}$ \\
\hline
\end{tabular}

Table 2:- Comparison of Clinical Vision Assessment under Glare Conditions

\section{Macular Pigment approach to glare reduction:-}

Macular pigment (MP) is the shared name for 3 isomeric carotenoids: lutein (L), zeaxanthin (Z), and mesozeaxanthin (MZ) which characterizes roughly $36 \%, 18 \%$, and $18 \%$ of total retinal carotenoid content, respectively ${ }^{33}$. The level of carotenoids comprising MP within the retina rises more than $1000 \mathrm{X}$ above levels found in serum suggesting a specific role in human vision ${ }^{34}$. MP is distributed across the retina with a peak density in the central $1^{\circ}$ of the macula with an exponential decay function falling to insignificant levels around $8^{\circ}$ of foveal eccentricity ${ }^{35}$. Bernstein et al. provided an overview of MP location and distribution within the retina: $\mathrm{L}$ and $\mathrm{Z}$ are incorporated at the location of the fovea within the outer plexiform layer, or Henle fiber layer, which is comprised of cone receptor axons and in the parafovea within the inner plexiform layer of the retina ${ }^{36} . \mathrm{L}$ is found in greater levels within the peripheral retina as the ratio of L:Z inverts from nearly 1:2.4 at the fovea to $2: 1$ in the peripheral retina ${ }^{34,37}$. Trieschmann et al. found that the density and distribution of MP differs among individuals and that spatial 
distribution measurements did not show a strong relationship with peak MP density found at the fovea ${ }^{38}$. This finding may underscore the importance that any MP measurement method must account for the density of foveal MP levels and the existing spatial distribution profile.

Disability glare has been established as dependent on the overall luminance created by a light source. As discussed above, literature supports that the effects of MP screening of glare could be found as a function of target veiling luminance $^{17,21,39}$. These effects were also found to be relative to MPOD and tended to be influenced by the spectral characteristics of the glare source. MP will not decrease glare disability unless the source contains substantial portions of short wavelength light ${ }^{17}$. High MPOD levels may lead to a reduction in photostress recovery time and glare discomfort, but does not increase target visibility or decrease glare disability if the target and surround luminance share the same wavelength conditions.

It has been identified that MPOD has a positive effect on disability glare which suggests that MPOD may also have a role in the reduction of intraocular straylight ${ }^{40,41}$. Puell et al. found that inter-subject differences in foveal MPOD showed a significant correlation with intraocular scatter in healthy, non-cataractous eyes ${ }^{42}$. Kvansakul et al. found that in addition to lower contrast acuity thresholds, intraocular scatter and root-mean-square (RMS) values showed a decreasing trend with lutein and zeaxanthin supplementation ${ }^{28}$. Results showed the degree of visual discomfort was significantly higher if the glare source contained short wavelength light compared to mid and long wavelength visible light ${ }^{21,39}$. Their results further identified that in subjects with higher levels of MPOD, a greater intensity of short wavelength light was required to produce an avoidance response. In retinal eccentricities larger than $10^{\circ}$ where MP levels are insignificant, significantly less intensity of short wavelength light was required to elicit the same avoidance response.

Stringham et al. posited that the global effects produced by MP optical filtration are greater when incorporated across wavelengths in contrast to narrow-band short-wavelength sources ${ }^{17}$. Importantly, their work recognized that MP effects on glare disability result from the spectral characteristics of the light source. MP will not decrease glare disability if the glare source does not contain a substantial amount of short-wavelength visible light ${ }^{17}$. Increased MPOD will not decrease glare disability when the wavelength of the target and the wavelength of the background are the same ${ }^{17}$. If MP absorbs short wavelength light from the target and background in equivalent amounts, the ratio will remain comparable regardless of the MP density level. In this instance, high MPOD may diminish visual discomfort but it will not increase target visibility ${ }^{43,44}$. Strictly speaking, MP does not provide direct optical absorption of the glare source but instead filters the masking luminance of the target proportional to the MPOD. A 2002 review article summarizes the mathematical derivation of the atmospheric haze coefficient by integrating the CIE photopic luminosity function and the spectral energy of the natural illuminant ${ }^{4}$. The authors proposed that the non-image forming portion of atmospheric light acts as a veiling luminance with respect to the targets seen through it. In addition, the background luminance tends to becomes short-wavelength dominant as the viewing distance increases. The object luminance tends to decrease and become short-wavelength deficient as the viewing distance increases. MP absorbs wavelengths primarily in the 410-500nm range and will have a quantitatively different effect on the background versus object luminance.

The cone axons project from the central fovea to form the outer plexiform layer or Henle fiber layer and Sujak et al. suggested that the anatomic structure of the axon layer causes $\mathrm{L}$ and $\mathrm{Z}$ to possess dichroic properties ${ }^{45}$. The perpendicular membrane orientation of both $\mathrm{L}$ and $\mathrm{Z}$ within the radial projections of the Henle fiber layer may allow specific absorption of plane-polarized light. Hemenger revealed that macular pigment exhibits these dichroic properties and may reduce glare disability through selective absorption of polarized light ${ }^{46}$. Haidinger's brush phenomena are a result of the dichroic properties of $\mathrm{L}$ and $\mathrm{Z}^{47}$. These identified dichroic properties are likely derived from the perpendicular arrangement of zeaxanthin and the non-orthogonal positioning of lutein within the lipid membrane layer referenced above ${ }^{48}$.

The dichroic nature of $\mathrm{MP}^{49}$, with its major axis of absorption oriented tangential to a circle centered on the fovea ${ }^{50}$, and the resulting polarizing effects such as Haidinger's brush have long been recorded. Reading and Weale first introduced the role of MP on longitudinal chromatic aberration ${ }^{51}$ and Thibos $^{52}$ confirmed that, in reference to lateral chromatic aberration, highly selective filtering by MP extending from 410-520nm increased target contrast by a level that increases with spatial frequency to a factor of $\sim 1.5$ at the spatial resolution limit. The proposed role of MP in preferential absorption of plane polarized light may be related to lower RMS aberration values associated with enhanced visual function ${ }^{28,53}$. 


\section{Conclusion:-}

Within the realm of current literature, 3 primary roles for the function of MP have been described: Protection, Optical, and Neural Efficiency (Table 3).

\begin{tabular}{|c|c|}
\hline Protection & $\begin{array}{l}\text { - Dependent upon both chemical structure and spectral absorption properties } \\
\text { - Tissue-protective effects provided by short wavelength light absorption and antioxidant } \\
\text { capabilities } \\
\text { - Peak absorbance at } 460 \mathrm{~nm} \text { and highest level found within axon layers (prereceptoral) and } \\
\text { also located within photoreceptor outer segments }\end{array}$ \\
\hline Optical & - $\quad$ Dependent upon spectral absorption properties and prereceptoral anatomic location \\
\hline $\begin{array}{l}\text { Neural } \\
\text { Efficiency }\end{array}$ & $\begin{array}{l}\text { - Preferential accumulation within non-mitotic CNS tissue } \\
\text { - Studies indicating a role for xanthophylls in axon cytoarchitecture, gap junction } \\
\text { communication, cognitive function, and location within frontal and occipital lobes }\end{array}$ \\
\hline
\end{tabular}

Table 3:- Three primary hypothesis of macular pigment function

All 3 proposed functions derived their hypotheses directly from structural attributes and physiologic characteristics MP. The Optical Hypotheses were first posited by Walls and Judd referencing an "intraocular yellow filter" 54 and later expanded by Nussbaum et al. in which macular pigment is specifically referenced ${ }^{55}$. Both summaries shared common ideas for the principle functions of an "Optical Hypothesis" (Table 4). These principle functions are:

1) The improvement visual acuity by a reduction of chromatic aberration

2) The promotion of comfort by a reduction of glare

3) The improvement of detail by atmospheric blue-haze absorption (Visibility)

4) The contrast enhancement by selective short wavelength light attenuation (Visibility)

\begin{tabular}{|l|l|}
\hline Acuity Hypothesis & Improvement predicated on screening of both scattered and aberrated short wavelength light \\
\hline Glare Hypothesis & $\begin{array}{l}\text { Derived from selective filtering properties of short wavelength light and reduction of forward } \\
\text { scatter }\end{array}$ \\
\hline $\begin{array}{l}\text { Visibility } \\
\text { Hypothesis }\end{array}$ & $\begin{array}{l}\text { Results from particle-dependent scatter occurring in natural environment and increasing } \\
\text { along a wave path }\end{array}$ \\
\hline
\end{tabular}

The Optical Hypothesis posits macular pigment filters short-wavelength visible light causing an attenuation of chromatic aberrations and light scatter. This suggested function is derived from a consideration of both physical and physiologic optics. The primary focus of the Optical Hypothesis is the idea that macular pigment enhances visual performance through optical filtration effects and anatomical location within the inner layers of the macula. According to Stringham et al., MP does not directly influence the blue cone function or S-cone channel due to an adjustment in gain by the S-cone pathway that may compensate for variations in MP filtering ${ }^{56}$. The prereceptoral short wavelength attenuation effect on $\mathrm{M}$ and $\mathrm{L}$ cones would likely be small and partially removing the short wavelength (blue) light would not be a very effective mechanism in isolation. This advocates a multifaceted function to MP which encompasses several simultaneous physiological and optical roles.

The Optical Hypothesis of macular pigment can be viewed as 3 elements: Acuity Hypothesis, Glare Hypothesis and the Visibility Hypothesis. The underlying characteristics of macular pigment along with the 3 elements of the Optical Hypothesis may be able to address the fundamental descriptions of glare including disability glare, discomfort glare, scotomatic glare, and dazzling glare. The spatial distribution of the lutein and zeaxanthin components which comprise MP may allow for a tailored approach to oral supplementation. For example, Disability glare may show the most significant response to zeaxanthin supplementation due to the 1:2.4 foveal ratio of L:Z.

Discomfort glare may show the most significant response to lutein supplementation due to the 2:1 parafoveal ratio of L:Z. Dazzling glare and scotomatic glare may benefit the greatest from an equally high L:Z supplement to address the dual nature of the glare symptoms.

Glare is a commonly encountered clinical finding demonstrating substantial diversity in etiology, visual performance decrement, severity and associated conditions. The potential mitigation of glare symptoms though 
lutein and zeaxanthin supplementation has been clearly established in the literature allowing for increased treatment options, conjunction with ophthalmic material solutions, for both clinicians and patients.

\section{References:-}

1. Vos JJ. Reflections on glare. Lighting Research \& Technology. 2003;35(2):163-175.

2. Vos JJ. On the cause of disability glare and its dependence on glare angle, age and ocular pigmentation. Clinical and experimental optometry. 2003;86(6):363-370.

3. Vos JJ, Boogaard J. Contribution of the cornea to entoptic scatter. Journal Optical Society America. 1963:53(7):869-873.

4. Wooten BR, Hammond BR. Macular pigment: influences on visual acuity and visibility. Progress in retinal and eye research. 2002;21(2):225-240.

5. Hemenger RP. Sources of intraocular light scatter from inversion of an empirical glare function. Applied optics. 1992;31(19):3687-3693.

6. Whitaker D, Steen R, Elliott DB. Light scatter in the normal young, elderly, and cataractous eye demonstrates little wavelength dependency. Optometry \& Vision Science. 1993;70(11):963-968.

7. Wooten BR, Geri GA. Psychophysical determination of intraocular light scatter as a function of wavelength. Vision research. 1987;27(8):1291-1298.

8. Vos JJ. Disability glare--a state of the art report. Commission International de l'Eclairage Journal. 1984;2:3953.

9. Van Den Berg TJTP, Tan KE. Light transmittance of the human cornea from 320 to $700 \mathrm{~nm}$ for different ages. Vision research. 1994;34(11):1453-1456.

10. Coppens JE, Franssen L, van den Berg TJ. Wavelength dependence of intraocular straylight. Experimental eye research. 2006;82(4):688-692.

11. Franssen L, Coppens JE, van den Berg TJ. Compensation comparison method for assessment of retinal straylight. Investigative Ophthalmology \& Visual Science. 2006;47(2):768-776.

12. van den Berg TJ. Analysis of intraocular straylight, especially in relation to age. Optometry \& Vision Science. 1995;72(2):52-59.

13. Fletcher LM, Engles M, Hammond BR. Visibility through atmospheric haze and its relation to macular pigment. Optometry \& Vision Science. 2014;91(9):1089-1096.

14. Nourrit V, Kelly JM. Intraocular scatter and visual performances. Optom Pract. 2009;10:117-28.

15. Aguirre R, Barraza J, Colombo E. The effect of glare on visibility depends on spatial frequency. Journal of Vision. 2007;7(9):259-259.

16. Aslam TM, Haider D, Murray IJ. Principles of disability glare measurement: an ophthalmological perspective. Acta Ophthalmologica. 2007;85(4):354-360.

17. Stringham JM, Hammond BR. The glare hypothesis of macular pigment function. Optometry \& Vision Science. 2007;84(9):859-864.

18. Van den Berg TJTP. On the relation between glare and straylight. Documenta Ophthalmologica. 1991;78(34):177-181.

19. Digre KB, Brennan KC. Shedding light on photophobia. Journal of Neuro-ophthalmology. 2012;32(1):68.

20. Stringham JM, Fuld K, Wenzel AJ. Action spectrum for photophobia. JOSA A. 2003;20(10):1852-1858.

21. Stringham JM, Fuld K, Wenzel AJ. Spatial properties of photophobia. Investigative ophthalmology \& visual science. 2004;45(10):3838-3848.

22. Lapid-Gortzak R, van der Meulen IJ, Nieuwendaal CP, van den Berg TJ. Alleviating debilitating photophobia and secondary exotropia caused by increased straylight by widening a small posterior capsulotomy. Journal of Cataract \& Refractive Surgery. 2011;37(2):413-414.

23. Mainster MA, Turner PL. Glare's causes, consequences, and clinical challenges after a century of ophthalmic study. American journal of ophthalmology. 2012;153(4):587-593.

24. Bargary G, Furlan M, Raynham PJ, Barbur JL, Smith AT. Cortical hyperexcitability and sensitivity to discomfort glare. Neuropsychologia. 2015;69:194-200.

25. Pokorny J, Cao D. Rod and cone contributions to mesopic vision. Proceedings of CIE 2010 Lighting Quality \& Energy Efficiency. 2010;9-20.

26. Sheehy JB. Dazzling glare: Protection criteria versus visual performance. Interim report, September 1985August 1990. Naval Air Development Center, Warminster, PA (USA).

27. Olson RJ, Werner L, Mamalis N, Cionni R. New intraocular lens technology. American journal of ophthalmology. 2005;140(4):709-716. 
28. Kvansakul J, Rodriguez-Carmona M, Edgar DF, Barker FM, Koëpcke W, Schalch W, Barbur JL. Supplementation with the carotenoids lutein or zeaxanthin improves human visual performance. Ophthalmic and Physiological Optics. 2006;26(4):362-371.

29. Kvansakul J, Rodriguez-Carmona M, Edgar DF, Barker FM, Koëpcke W, Schalch W, Barbur JL. Supplementation with the carotenoids lutein or zeaxanthin improves human visual performance. Ophthalmic and Physiological Optics. 2006;26(4):362-371.

30. Jungnickel H, Babovsky H, Kiessling A, Gebhardt M, Grein HJ, Kowarschik R. Effects on vision with glare after correction of monochromatic wavefront aberrations. Journal of Refractive Surgery. 2011;27(8):602-612.

31. McDonald JE, Kotb AMEM, Decker BB. Effect of brimonidine tartrate ophthalmic solution $0.2 \%$ on pupil size in normal eyes under different luminance conditions. Journal of Cataract \& Refractive Surgery. $2001 ; 27(4): 560-564$.

32. Kesler A, Shemesh G, Rothkoff L, Lazar M. Effect of brimonidine tartrate $0.2 \%$ ophthalmic solution on pupil size. Journal of Cataract \& Refractive Surgery. 2004;30(8):1707-1710.

33. Beatty S, Boulton M, Henson D, Koh HH, Murray IJ. Macular pigment and age related macular degeneration. British Journal of Ophthalmology. 1999;83(7):867-877.

34. Landrum JT, Bone RA, Joa H, Kilburn MD, Moore LL, Sprague KE. A one year study of the macular pigment: the effect of 140 days of a lutein supplement. Experimental eye research. 1997;65(1):57-62.

35. Hammond BR, Johnson EJ, Russell RM, Krinsky NI, Yeum KJ, Edwards RB, Snodderly DM. Dietary modification of human macular pigment density. Investigative ophthalmology \& visual science. 1997;38(9):1795-1801.

36. Bernstein PS, Delori FC, Richer S, van Kuijk FJ, Wenzel AJ. The value of measurement of macular carotenoid pigment optical densities and distributions in age-related macular degeneration and other retinal disorders. Vision research. 2010;50(7):716-728.

37. Bone RA, Landrum JT, Fernandez L, Tarsis SL. Analysis of the macular pigment by HPLC: retinal distribution and age study. Investigative ophthalmology \& visual science. 1988;29(6):843-849.

38. Trieschmann M, Van Kuijk FJGM, Alexander R, Hermans P, Luthert P, Bird AC, Pauleikhoff D. Macular pigment in the human retina: histological evaluation of localization and distribution. Eye. 2008;22(1):132.

39. Stringham JM, Hammond BR. Macular pigment and visual performance under glare conditions. Optometry and Vision Science. 2008;85(2):82-88.

40. Stringham JM, Garcia PV, Smith PA, McLin LN, Foutch BK. Macular pigment and visual performance in glare: benefits for photostress recovery, disability glare, and visual discomfort. Investigative ophthalmology \& visual science. 2011;52(10):7406-7415.

41. Hammond BR, Wooten BR, Engles M, Wong JC. The influence of filtering by the macular carotenoids on contrast sensitivity measured under simulated blue haze conditions. Vision research. 2012;63:58-62.

42. Puell MC, Palomo-Alvarez C, Barrio AR, Gómez-Sanz FJ, Pérez-Carrasco MJ. Relationship between macular pigment and visual acuity in eyes with early age-related macular degeneration. Acta ophthalmologica. 2013;91(4).

43. Renzi LM, Hammond BR. The relation between the macular carotenoids, lutein and zeaxanthin, and temporal vision. Ophthalmic and Physiological Optics. 2010;30(4):351-357.

44. Wenzel AJ, Fuld K, Stringham JM, Curran-Celentano J. Macular pigment optical density and photophobia light threshold. Vision research. 2006;46(28):4615-4622.

45. Sujak A, Okulski W, Gruszecki WI. Organisation of xanthophyll pigments lutein and zeaxanthin in lipid membranes formed with dipalmitoylphosphatidylcholine. Biochimica et Biophysica Acta-Biomembranes. 200;1509(1):255-263.

46. Hemenger RP. Dichroism of the macular pigment and Haidinger's brushes. JOSA. 1982;72(6):734-737.

47. Bone RA, Landrum JT, Tarsis SL. Preliminary identification of the human macular pigment. Vision research. 1985;25(11):1531-1535.

48. N'soukpoé-Kossi CN, Sielewiesiuk J, Leblanc RM, Bone RA, Landrum JT. Linear dichroism and orientational studies of carotenoid Langmuir-Blodgett films. Biochimica et Biophysica Acta-Biomembranes. 1988;940(2):255-265.

49. Bone RA, Landrum JT. Distribution of macular pigment components, zeaxanthin and lutein, in human retina. Methods in enzymology. 1992; 213:360-366.

50. Snodderly DM, Auran JD, Delori FC. The macular pigment. II. Spatial distribution in primate retinas. Investigative ophthalmology \& visual science. 1984;25(6):674-685.

51. Reading VM, Weale RA. (1974). Macular pigment and chromatic aberration. JOSA. 1974;64(2):231-234. 
52. Thibos LN. Calculation of the influence of lateral chromatic aberration on image quality across the visual field. JOSA A. 1987;4(8):1673-1680.

53. Bone RA. MP in Henle fiber membranes: Model for Haidinger's brushesXXXXXXXXXX

54. Walls GL, Judd HD. The intra-ocular colour-filters of vertebrates. British journal of ophthalmology. 1933;17(11):641.

55. Nussbaum JJ, Pruett RC, Delori FC. MACULAR YELLOW PIGMENT: The First 200 Years. Retina. 1981;1(4):296-310.

56. Stringham JM. Compensation for light loss resulting from filtering by macular pigment: relation to the S-cone pathway. Optometry \& Vision Science. 2006;83:887-894. 